\title{
DRUG INTOXICATION AT THE CRITICAL CARE AND TOXICOLOGY UNIT OF THE JOSEPH RAVOAHANGY ANDRIANAVALONA TEACHING HOSPITAL, ANTANANARIVO, MADAGASCAR
}

KEY WORDS: Drug Intoxications - Clinical signs Prognosis- Madagascar

Ramarolahy Rija Critical care and toxicology unit of the Joseph Ravoahangy Andrianavalona Niaina

Rakotomavo teaching hospital, Antananarivo, Madagascar

Falihery Albertin

Critical care unit of the Joseph Raseta Befelatanana teaching hospital, Antananarivo, Madagascar

Razafindraibe Faneva Angelo Parfait*

\section{Rakotoarison}

Ratsaraharimana Critical care and toxicology unit of the Joseph Ravoahangy Andrianavalona na Cathérine Critical care and toxicology unit of the Joseph Ravoahangy Andrianavalona teaching hospital, Antananarivo, Madagascar *Corresponding Author

Nicole

\section{Raveloson}

Nasolotsiry

Enintsoa teaching hospital, Antananarivo, Madagascar

Critical care unit of the Joseph Raseta Befelatanana teaching hospital, Antananarivo, Madagascar

Introduction: Drug intoxications are a major public health problem in the world. Our study consists in describing the clinical and evolutionary characteristics of drug intoxications.

Methods: It was a retrospective, cross-sectional and descriptive study of patients admitted to the critical care and toxicology unit of the Joseph Ravoahangy Andrianavalona teaching hospital, Antananarivo, Madagascar, from January to December 2013 for drug intoxications.

Results: One hundred and thirty-four patients were retained during the study period. A female predominance was noted (52.23\%). The average age of the patients was $26.12 \pm 13.28$ years old. Psychotropic drugs (27.6\%) and analgesics $(14.9 \%)$ were the most incriminated drugs. Intoxication was voluntary in $90 \%$ of cases. Neuromuscular disorders $(56.71 \%)$, cardiovascular disorders $(55.22 \%)$ and respiratory disorders $(35.07 \%)$ were the most observed types of disorders. Patients' evolution was favourable in $99.2 \%$ of cases.

Conclusion: Drug intoxication is a frequent reason for admission to our department with a favourable prognosis. Prevention remains the best way to fight against intoxications.

\section{INTRODUCTION:}

Drug intoxications are a real scourge in many countries around the world, thus a frequent cause of admission to the emergencies and the recovery department [1].

In France the incidence of drug intoxications has steadily increased for about 30 years, from 1-1.5 intoxications per 1,000 inhabitants in 1970 to 5-6 intoxications per 1,000 inhabitants in 1990 [2]. In the United States, in the State of Utah, there was a five-time increase in the number of toxic deaths from 79 in 1991 to 391 in 2003 [3]. Mortality due to drug intoxications is quite significant. There are more than 2,000 deaths from drug intoxications every year in France [4]. The objectives of this study were to describe the clinical and evolutionary characteristics of drug intoxications seen at the critical care and toxicology unit of the Joseph Ravoahangy Andrianavalona teaching hospital, Antananarivo, Madagascar.

\section{PATIENTS AND IMETHODS:}

This was a retrospective, cross-sectional and descriptive study carried out in the critical care and toxicology unit of the Joseph Ravoahangy Andrianavalona teaching hospital, Antananarivo, Madagascar, over a 12-month period from January to December 2013. All patients admitted for drug intoxication, regardless of age and gender, were included in the study. All patients whose records were incomplete and/or inoperative were excluded from the study. Results are expressed in number and percentage.

|www.worldwidejournals.com |

\section{RESULTS:}

One hundred and thirty-four patients were retained during the study period. The average age of patients was $26.12+/-$ 13.28 years old with a female predominance $(52.23 \%)$. The majority of patients had no particular history (91.04\%).Table I shows the distribution of patients according to the presence of antecedents.

Table I: Patient distribution according to antecedents

\begin{tabular}{|l|l|l|}
\hline Antecedents & Effective (n=134) & Percentage (\%) \\
\hline No antecedent & 122 & 91.04 \\
\hline HBP* & 05 & 3.73 \\
\hline Epilepsy & 2 & 1.49 \\
\hline Diabetes & 1 & 0.74 \\
\hline Asthma & 1 & 0.74 \\
\hline Neurocisticercosis & 1 & 0.74 \\
\hline Heart failer & 1 & 0.74 \\
\hline Psychiatric antecedent & 1 & 0.74 \\
\hline Total & 134 & 100 \\
\hline
\end{tabular}

HBP*: high Blood Pressure

Psychotropic drugs (27.6\%) and analgesics (14.9\%) were the most incriminated drugs.

An intake of multiple medications was noted in $42.5 \%$ of cases. The intoxication was voluntary in $90 \%$ of the cases. The Table II shows the distribution of drug intoxications according to the drugs used. 
Table II: Distribution of drug poisoning according to the drug used

\begin{tabular}{|l|c|c|}
\hline Types of drugs & Effective $(\mathrm{n}=134)$ & Percentage (\%) \\
\hline Psychotropic & 37 & 27.6 \\
\hline Antalgesic & 20 & 14.9 \\
\hline Cardiotoxic & 11 & 8.2 \\
\hline Antibiotic & 5 & 3.7 \\
\hline Antihypertensive & 3 & 2.2 \\
\hline Antimalarial & 2 & 1.5 \\
\hline Anti-inflammatory & 1 & 0.7 \\
\hline Progestin & 1 & 0.7 \\
\hline Anticholinergic & 1 & 0.7 \\
\hline Bronchodilatator & 1 & 0.7 \\
Anti-giddiness & 1 & 0.7 \\
\hline Multiple drug & 51 & 38.1 \\
\hline Total & 134 & 100 \\
\hline
\end{tabular}

Neuromuscular disorders (56.71\%), cardiovascular disorders $(55.22 \%)$ and respiratory disorders (35.07\%) were the most observed types of disorders. The Table III shows the distribution of patients according to the types of disorders presented by the patients. All patients were given gastric lavage regardless of the time they arrived at the hospital. Patients' evolution was favourable in $99.2 \%$ of cases. One patient, i.e. $0.74 \%$, died as a result of bronchial congestion.

Table III: Distribution of patients according to the types of disorders presented by the patients

\begin{tabular}{|l|c|c|}
\hline Types of disorders & Effective $(\mathrm{n}=134)$ & Percentage $(\%)$ \\
\hline Neuromuscular disorders & 76 & 56.71 \\
\hline Cardiovascular disorders & 74 & 55.22 \\
\hline Respiratory disorders & 47 & 35.07 \\
\hline Hemodynamic disorders & 46 & 34.32 \\
\hline Digestive disorders & 29 & 21.64 \\
\hline
\end{tabular}

One patient can have 2 types of disorders

\section{DISCUSSION:}

In our context, young people are the most affected by drug intoxications. This result confirms the African data concerning acute drug intoxications. Guindo T et al [5] reported in a retrospective study at Point "G" hospital that in $71.2 \%$ of cases the age was between 21 and 40 years old. At the psychiatric hospital in Tunis, the average age of suicide attempts by drug intoxications was 25 years old [6]. In Europe, however, the elderly, victims of social exclusion are more exposed to the risk of suicidal intoxications [7].

In terms of gender, a slight female predominance was observed in our series. In Morocco, according to Badrane Narjis et al [8], female young adults and adolescents are the most affected by voluntary intoxications, most often suicidal. The factors of toxic suicide risk are the socio-economic and psychic factors. The use of the drug in suicide is common because the drug is easy to obtain and consume [9]. Contrarily, Baud FJ and his teams [10] counted 73 male cases out of 130 cases of drug intoxications.

Psychotropic drugs (27.6\%) and analgesics (14.9\%) were the most incriminated drugs in our study. The type of medicines varies from one country to another one. Numerous studies conducted in France have shown a predominance of psychotropic drugs in voluntary drug intoxications [7, 11-13]. According to Stailkowsky et al [13] in 2001 and 2002, 55\% of voluntary intoxications in France were caused by benzodiazepines. Paracetamol would be the drug the most frequently found in acute intoxications in Great Britain [14]. In Mali, the study by Maiga et al [15] found a predominance of antimalarial drugs, particularly chloroquine (50.9\%).

In terms of clinical signs, neuromuscular disorders (56.71\%), cardiovascular disorders (55.22\%) and respiratory disorders $(35.07 \%)$ were the most observed types of disorders in our series. Symptoms vary depending on the type and amount of medicines consumed. The most frequent neurological manifestations gather all levels of impairment of consciousness up to coma. In France, neuroleptic intoxications seem to remain stable, however the percentage varies between $4.7 \%$ and $8.4 \%$ [16]. Respiratory complications due to the alteration of consciousness ((central respiratory depression, mechanical upper airway obstruction, inhalation pneumopathy) are frequent during drug intoxications and may alter the prognosis of a priori benign intoxications or extend the stay in intensive care [17-18].

In our study, the evolution of drug intoxications was favourable in $99.2 \%$ of cases. Guindo $\mathrm{T}$ et al [5] counted two deaths out of 104 cases of intoxications, i.e. $1.9 \%$. According to Maiga [15], the mortality of drug intoxication would be linked to several factors which are the nature and the quantity ingested the reason for intoxication, the prior state of health of the intoxicated, the particular sensitivity of each person, the combination of several toxins and the time taken to take care.

\section{CONCLUSION:}

Drug intoxication is a frequent reason for admission to the the critical care and toxicology unit of the Joseph Ravoahangy Andrianavalona teaching hospital, Antananarivo, Madagascar. Young, female subjects are the most affected. Psychotropic drugs and analgesics are the most incriminated drugs. The evolution is favourable in the majority of the cases. Prevention remains the best way to fight against drug intoxication.

\section{Conflicts of interest}

The authors declare no conflict of interest

\section{Funding statements}

This study was not funded

\section{REFERENCES}

1. Hantson P, Baud FJ. 1995. Intoxications aiguës médicamenteuses. Encyclopédie Médico-Chirurgicale. Toxicologie-Pathologie professionnelle, 16-001-G-10. Paris :Éditions Techniques.

2. Lambert H, Manel J, Bellou A, El Kouch S. Morbidité et mortalité par intoxications médicamenteuses aiguës en France. Revue Praticien $1997 ; 47$ : 716-20

3. Centers for Disease Control and Prevention. Increase in poisoning deaths caused by non-illicit drugs, Utah, 1991-2003. In: Adnet F et al. Réanimation-14 (2005): :21-726.

4. OMS. Prise en charge des intoxications. Manuel de l'agent de santé $1999 ; 6$ : 15-099.

5. Guindo T. Intoxications médicamenteuses à l'hôpital du Point « $G$ » Thèse de Médecine,Bamako, 2005.

6. Ellouze E, Cheour M, Elloueze S, Khaloui A, Hsairi A. Tentatives de suicide par intoxication médicamenteuse. Etude épidémiologique à l'hôpital psychiatrique de Tinus. Revue Française Psychiatrie et Psychologie Medicale 2005 ; IX (87) : $41-45$.

7. Wink P. Les facteurs socio familiaux et médicopsychiatriques dans les tentatives de suicide. Etude épidémiologique. Thèse de Médecine, Nancy 1996.

8. Badrane narjis, Abadi fatima, Ouammi lahcen, Soulaymani-Bencheikh Rachida. Intoxications médicamenteuses au Maroc : données du Centre Anti poison du Maroc (1980-2008). Toxicologie Maroc - $N^{\circ} 7.2010$.

9. Laure $P$, Binsinge $C R$. Les médicaments détournés: crimes, mésusages, pratiques addictives. Paris, Masson Armand Colin Scientifique Interéditions; 2003

10. Baud FJ. Nouveaux syndromes d'origine médicamenteuse. Revue du Praticien $1997 ; 47: 726-30$.

11. Atout S. Evolution des intoxications médicamenteuses volontaires entre 1994-1995 et 1999-2000.Thèse de Médecine,Paris 7,2004.

12. Billy F, Montaz L, Perault MC, Vandel B. Etude des intoxications médicamenteuses volontaires reçues dans une unité d'accueil des urgences. Therapies 1998;53:553-8.

13. Staikowsky F, Uzan D, Grillon $\mathrm{N}$ et al. Intoxications médicamenteuses volontaires reçues dans un service d'accueil des urgences. Revue Médicale de Liège 2006 ; 61 (3) : 185-189.

14. Hawton K, Simkin S, Deeks J. Coproscamal and suicide: a study of national mortality statistics and local nonfatal self poisoning. BMJ 2003;326:1006-8.

15. Maiga. Intoxications médicamenteuses aiguës au service des urgences du CHU Gabriel TOURE : à propos de 110 cas. Octobre 2005 à Septembre 2006. Thèse de Médecine, Gabriel Touré 2007.

16. Billy F, Montaz L, Perault M C, Vandel B. Étude des intoxications médicamenteuse volontaires reçues dans une unité d'accueil des urgences. Thérapie 1998;53:553-558.

17. Bradberry SM, Vale JA. Intoxications par les antidépresseurs. In: A. Jaeger and J.A.Val, Editors, Intoxications aiguës, Elsevier, Paris, 1999; pp. 232-248.

18. Isbister GK, Downes F, Sibbritt D, Dawson AH, Whyte IM. Aspiration pneumonitis in an overdose population: frequency, predictors and outcomes. Crit. Care.Med. $2004 ; 32$ : 88-93. 